\section{AN OXALATE-IODIDE PROCESS FOR PARIS GREEN ANALYSIS:}

By C. A. Peters and L. E. Fielding Received August 17, 1916

One of us $^{2}$ has shown that copper may be precipitated quantitatively as the oxalate, provided $40 \mathrm{mg}$. or more of copper salt are present in $50 \mathrm{cc}$. of liquid and that copper may be separated quantitatively from arsenic by this method.

In view of this fact it would seem simple to adapt the method to the determination of copper and arsenic in Paris green by precipitating the copper as the oxalate and determining the arsenic in the fitrate by oxidation with iodine. This paper outlines such a process.

In this precipitation of copper by oxalic acid, Peters ${ }^{3}$ separated copper oxalate in the presence of ro per cent nitric acid, finding that copper oxalate precipitated from neutral and faintly acidic solutions too fine to be retained on the filter. It was deemed wise to avoid the use of nitric acid in this process because of the possible oxidation of arsenic acid and, consequently, sulfuric acid was used to decompose Paris green. In order to determine how little sulfuric acid would be necessary to decompose the Paris green, $0.25 \mathrm{~g}$. of various samples of the latter were weighed out and treated with varying amounts of dilute sulfuric acid. To determine how completely the copper in these acid solutions could be precipitated by oxalic acid, the crystallized acid was added to the boiling hot liquid at the rate of $2 \mathrm{~g}$. to each $50 \mathrm{cc}$. and the filtrates after standing various lengths of time were tested for copper by potassium ferrocyanide in acetic acid solution. The data are presented in Table I.

$$
\text { TABLE I }
$$

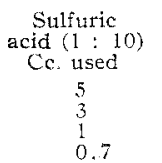

$\begin{array}{cc}\text { Volvme } & \mathrm{C}_{2} \mathrm{H}_{2} \mathrm{O}_{4} .2 \mathrm{H}_{2} \mathrm{O} \\ \text { Cc. } & \text { Grams } \\ 100 & 4 \\ 100 & 4 \\ 100 & 4 \\ 100 & 4\end{array}$

$\begin{array}{cc}\text { TEST WITH FERROCyANIDE } \\ \text { After I hout } & \text { After } 18 \text { hours } \\ \text { Strong } & \text { Faint } \\ \text { Strong } & \text { Faint } \\ \text { Strong } & \text { Very faint } \\ \text { Strong } & \text { Negligible }\end{array}$

It is evident from Table I that even $0.7 \mathrm{cc}$. of I : Io sulfuric acid is sufficient to decompose the Paris green. Tests showed copper to be present in all cases after standing I hour. When, however, the material stood over night, the tests for copper when only 0.7 cc. I : ro sulfuric acid was present were so faint as to be quantitatively negligible. These facts then outline the conditions under which Paris green is decomposed and the copper may be quantitatively precipitated.

In most of these experiments a slight precipitate was noticeable in the decomposed Paris green solution, the quantity varying with the different samples used. This was proved to be silica by filtering off a precipitate on paper, burning the paper and treating with hydrofluoric and sulfuric acids. Upon igniting and weighing the precipitate it lost two-thirds its weight, $0.0124 \mathrm{~g}$., showing the presence of silica in the precipitate. There being a possibility that the precipitate might hold some arsenic, the siliceous residue

1 From a thesis of $I_{\text {. }}$. E. Fielding, optionally presented for the degree of B.Sc. at the Massachusetts Agricultural College at Amherst.

2 Am. Jour. Sci. [4] 10, 359; also Gooch, "Methods in Chemical Analysis," p. 131

${ }^{3}$ Loc, cit. after digestion with acid was collected on asbestos and washed until the filtrates no longer acted on litmus. Then the precipitate was washed with a few drops of 30 per cent caustic soda. The caustic filtrate was neutralized with hydrochloric acid and again made alkaline with bicarbonate and treated with iodine. Only one drop was necessary to give permanent color, showing that no iodine was held by the silica.

To determine if the arsenic in the filtrate could be measured by iodine after neutralizing the oxalic acid present, a measured amount of the standard arsenite solution was drawn off, $2 \mathrm{~g}$. of oxalic acid added, and the solution neutralized with dry sodium bicarbonate and titrated with iodine. The addition of oxalic acid caused no change in the standard so that it may be assumed that the arsenic could be determined quantitatively in the filtrate from the copper oxalate precipitation.

The method as outlined is as follows: Weigh out about $0.25 \mathrm{~g}$. of Paris green in a small beaker, add less than I ce. of I : Io sulfuric acid and boil at a volume jo cc. for two minutes. While hot add cautiously and slowly $2 \mathrm{~g}$. of oxalic acid crystals, heat again to boiling and allow to stand over night. Filter off the precipitated copper oxalate onto an asbestos filter, wash the precipitate with a little water to carry all the arsenic into the filtrate, and replace the crucible, asbestos and precipitate in the original beaker. Add a convenient amount of water, 5 or to $\mathrm{cc}$. of $\mathrm{I}$ : I sulfuric acid, heat nearly to boiling and titrate with standard permanganate. From the amount of permanganate used the copper can be calculated.

Neutralize the oxalic acid and the sulfuric acid in the filtrate by adding dry sodium bicarbonate and, after an excess of bicarbonate has been added, run in standard iodine solution to color. From the iodine solution used the arsenic can be calculated.

The results of an analysis of the Paris green solution by the proposed method and by standard methods are given in Table II. For standard methods that described by Avery and Beans ${ }^{1}$ was used for arsenic, and the thiosulfate process as outlined by Gooch and Heath $^{2}$ was applied for the copper determination.

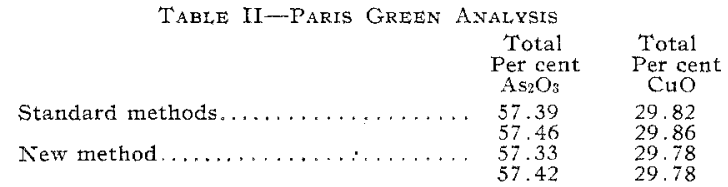

It is evident that the process possesses the same degree of accuracy as the one commonly used.

PRECAUTIONS-In adding the dry oxalic acid to the $50 \mathrm{cc}$. of solution from Paris green it is well to add the first few crystals slowly, as the solution is very apt to be in a superheated condition and will boil over if the whole mass of crystals is added at one time.

The end-point in the titration of the copper oxalate by the permanganate is naturally slow, depending upon the speed with which the oxalic acid is liberated. This depends in turn upon the concentration of the

1 J. Am. Chem. Soc., 23 (1901), 485.

121.

2 A m. Jour. Sci, [4] 24, 67; also Gooch, "Methods in Analysis," p. 
sulfuric acid and the temperature of the system. The end-point, however, is definite and cannot be overstepped. The presence of the asbestos is no objection.

\section{SUMMARY}

A method for the analysis of Paris green is proposed by which the copper is precipitated as the oxalate and the oxalic acid combined is titrated with permanganate, the arsenic being oxidized in the filtrate by iodine after being made alkaline. The procedure is accurate and, with the exception of the fact that the copper oxalate must stand over night, rapid.

Department of General, and Agricultural, Chemistry

Massachusetrs Agricultural, Coliege, Amherst

\section{THE DETERMINATION OF SULFUR IN IRON AND STEEL} By H. B. PULSIFER

Received July 17, 1916

In 1904 , Hendrixson announced ${ }^{1}$ that iron dissolves easily in chloric acid, going quantitatively to the ferric condition. At that time the author was studying the methods for the determination of sulfur in iron and steel and at once recognized the possibility of using chloric acid as the solvent in the analysis.

Chloric acid is a highly satisfactory solvent for the usual finely granular material used for analysis; the action takes place rapidly and with far less gas evolution than when nitric acid is the solvent. In attempting quantitative data on samples of known

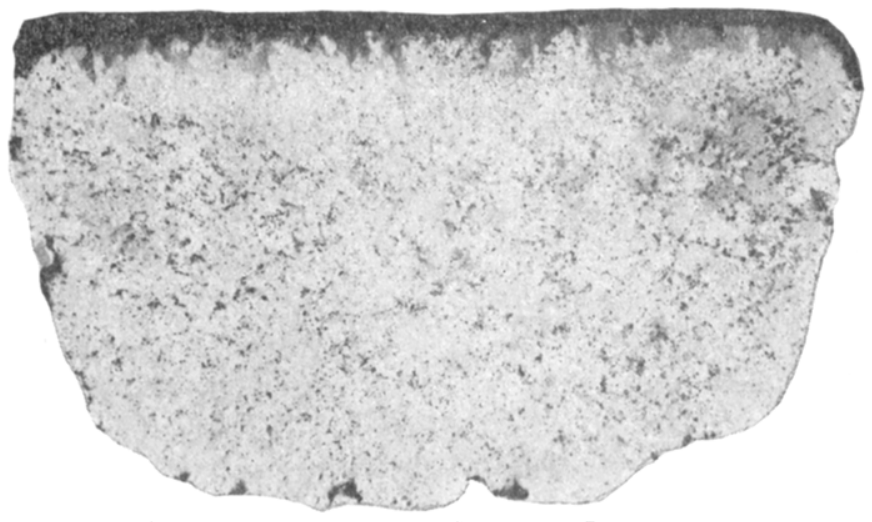

Fig. I-SUlfur Print of Cast IRON Ingot

sulfur content the work developed largely into a study of the uniformity of samples, the nitric acid and fusion methods, the precision of results and the work of others.

A limited number of analyses by the new method indicate the difficulties and possibilities of its use.

From the analytical point of view the segregation of sulfur in the ferrous materials was first mentioned by Eggertz in $1868 ;^{2}$ our Bureau of Standards has frequently related its difficulties along the same line, while Bauer and Deiss ${ }^{3}$ take particular pains to expound the difficulty and indicate how the analyst shall avoid falling into serious error.

This segregation of sulfur is a well known condition to the metallurgist and metallographer; with sulfur

1 J. Am. Chem. Soc., 26 (1904), 747.

2 Chem. News, 18 (1868), 15.

3 "Sampling and Chemical Analysis of Iron and Steel," translated by Hall and Williams, 1915. prints and through the microscope the actual condition is far more truthfully revealed than from the reports of the analyst who may rely on one single result or unwittingly fail to indicate the diversity of his check determinations.

The statistical method of studying the distribution of results would be highly illuminating but is hardly practical because of the material, time and labor required. In no case on the samples here studied were less than duplicate results obtained; often 3 and in several cases 6 or 7 determinations were run for the sake of establishing a mean value of the sulfur content.

PREPARATION OF SAMPLE

We suppose that sulfur occurs in our materials as sulfide of iron, sulfide of manganese, or indeed as a double sulfide of the two. These sulfides are probably quite insoluble in the more common $\alpha$ - and $\beta$-modifications of ferrite for we have no difficulty in discovering the particles with the microscope when only a few hundredths of one per cent of sulfur are present in the metal. This discrete occurrence of sulfur in the metal, and in particular its segregation in that portion of an ingot which solidifies last is perfectly well known to metallurgists and metallographers. The bearing of this on the results obtained by the analyst is highly significant. Even more imperative is its dictum regarding the preparation of the sample.

In a 5 -g. sample of metal it requires about 0.00005

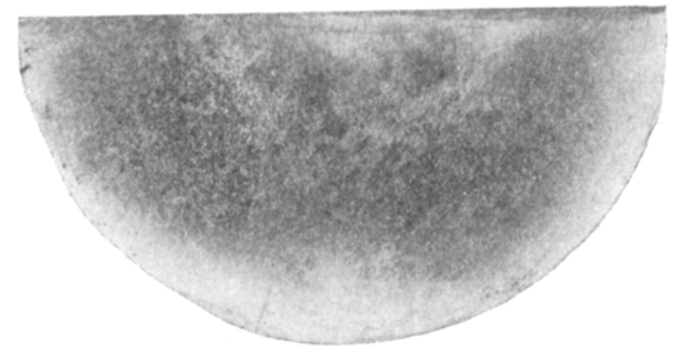

Fig. II-Sulfur Print of Steel, Shafting

g. of sulfur or $0.00014 \mathrm{~g}$. FeS or $\mathrm{MnS}$ to influence the analysis by $0.00 \mathrm{I}$ per cent. This is represented by a cube of the substance $0.3 \mathrm{~mm}$. on a side; such a particle will barely pass a 50-mesh screen. For some degree of safety, then, the material should pass an 8o-mesh screen and be thoroughly mixed; this material would be uniform to about $0.00 \mathrm{I}$ per cent, in 5 -g. lots. The actual loss of sulfur by such treatment awaits investigation. Variations due to analytical conditions might still cause deviations.

Figs. I to IV visualize this common characteristic of materials. Fig. I is a full-size sulfur print made by photographic paper on a small ingot of cast iron. It shows the spots of sulfide throughout the entire section and, in particular, the layer at the top which is extremely high in sulfur. The accurate sampling of such an ingot is obviously quite a task.

Analyses of crushed millings gave the following results: 